\title{
Inhibition of Mitochondrial Respiratory Chain Activity by O, O-Dimethyl- and 4-O- Methyl- Alpinumisoflavones
}

\author{
Augustine Ocloo ${ }^{1,3^{*}}$, Robert Kingsford-Adaboh ${ }^{2}$, Andrew J. Murray ${ }^{3}$ \\ ${ }^{1}$ Department of Biochemistry, Cell and Molecular Biology, School of Biological Sciences, College of Basic and Applied Sciences, University of Ghana, \\ Legon, P. O. Box LG54, Legon, Accra, Ghana. ${ }^{2}$ Department of Chemistry,School of Physical and Mathematical Sciences, College of Basic and Applied \\ Science, University of Ghana, Legon, Accra, Ghana. ${ }^{3}$ Department of Physiology, Development and Neuroscience, University of Cambridge, UK.
}

\begin{tabular}{|c|c|}
\hline ARTICLE INFO & ABSTRACT \\
\hline Article history: & Although the molluscicidal activity of crude dichloromethane extract of Millettia thonningii, known to be rich in \\
\hline Received on: 16/07/2016 & alpinumisoflavones was attributed to its inhibition of isolated rat liver mitochondrial complex I activity, the \\
\hline Accepted on: $16 / 11 / 2016$ & effects of the constituent alpinuisoflavones on mitochondrial function have not been reported. The present study, \\
\hline Available online: 30/03/2017 & therefore investigated the effect of $\mathrm{O}$, O-dimethyl-alpinumisoflavone, a constituent of the crude \\
\hline Key words: & $\begin{array}{l}\text { dichloromethane extract of } M \text {. thonningil seeds and } 4-0 \text {-methyl-alpinumsioflavone, a naturally occurring } \\
\text { alpinumisoflavone in Lonchocarpus glabrescens in isolated rat liver mitochondria and permeabilised mouse }\end{array}$ \\
\hline $\begin{array}{l}\text { Mitochondrial respiratory } \\
\text { complexes, inhibition, } \\
\text { alpinumisoflavones. }\end{array}$ & $\begin{array}{l}\text { heart fibers using substrate-inhibitor titrations. The O, O-dimethyl-alpinumisoflavone inhibited State } 3 \\
\text { respirations supported by glutamate/malate (complex I), succinate (complex II) and Ascorbate/TMPD (complex } \\
\text { IV) in the permeabilised cardiac tissues but inhibited only the State } 3 \text { respiration supported by glutamate } \\
\text { (complex I) in the isolated rat liver mitochondria. The } 4 \text { '-O-methyl-alpinumsioflavone on the other hand } \\
\text { inhibited State } 3 \text { respirations supported by all the substrates in both the isolated rat liver mitochondria and the } \\
\text { permeabilised cardiac tissues. Thus, whilst O, O-dimethyl-alpinumisoflavone, a naturally occurring phyto- } \\
\text { compound in the extract of } M \text {. thonningii seeds inhibits mitochondrial respiratory chain activity essentially at } \\
\text { complex I, its derivative } 4 \text { '-O-methyl-alpinumisoflavone, a naturally occurring phytocompound in Lonchocarpus } \\
\text { glabrescens inhibits mitochondrial respiratory complexes I, II and IV. }\end{array}$ \\
\hline
\end{tabular}

\section{INTRODUCTION}

Mitochondria are very important and unique organelles in the eukaryotic cell. This is because in addition to producing about $90 \%$ of the energy necessary for cell survival (Kuhlbrandt, 2015), they perform other important functions including redox signaling (Moncada, 2010), calcium homeostasis (Giorgi et al.., 2012) and play a crucial mediating role in programmed cell death (apoptosis) (Tait and Green, 2010). Furthermore, mitochondria have unique properties in that, they are the only mammalian

\footnotetext{
* Corresponding Author

Augustine Ocloo, Department of Biochemistry, Cell and Molecular Biology, School of Biological Sciences, College of Basic and Applied Science, University of Ghana, Legon, P. O. Box LG54, Legon, Accra, Ghana.Email: aocloo @ ug.edu.gh
}

cellular organelles that contain their own DNA (Greaves et al.., 2012), the inner membrane is rich in cardiolipin and their interior is negatively-charged (alkaline) (Wallace and Starkov, 2000). These specialised structural and functional characteristics of the mitochondrion provide a number of primary and secondary targets for xenobiotics. Consequently, mitochondria are sensitive to many compounds. Thus, a number of synthetic chemicals and natural compounds including plant phytochemicals manifest their effects by interfering with mitochondrial function (Forbes-Hernandez et al.., 2014; Gohil et al.., 2010; Toogood, 2008). Millettia thonningii (Schum-Thonn) Baker is a deciduous tree that can attain a height of up to $20 \mathrm{~m}$ and a short bole of diameter up to $1 \mathrm{~m}$ with a dense crown (Harrison et al.., 2011). It is a leguminous plant, traditionally used for several medicinal purposes (Banzouzi et al.., 2008). 
The dichloromethane extract of the seeds is known for its molluscicidal property (Evans et al.., 1986; Tang et al.., 1995; Squire and Whitfield, 1989; Perret et al., 1994; Lyddiard et al.., 2002) and has been reported to reduce miracidial motility (Lyddiard et al.., 1998) by inhibiting the complex I of mitochondrial respiratory chain (Lyddiard and Whitfield, 2001). M. thonningii seeds are rich in alpinumisoflavones. Alpinumisoflavones are pyranoisoflavonoids, which are flavonoids possessing a pyran group (Kingsford-Adaboh et al., 2006). They occur naturally in a number of plants of medicinal importance and have been isolated and established to be responsible for many of the medicinal properties of these plants (Kingsford-Adaboh et al., 2006; Namkoong et al.., 2011). On the basis of structural similarity between the alpinumisoflavones and rotenone, a potent inhibitor of mitochondrial complex I, the reported inhibition of energy metabolism (Lyddiard et al.., 1998) and cytotoxicity (Evans et al.., 1986; Tang et al.., 1995; Squire and Whitfield, 1989; Perret et al., 1994; Lyddiard et al.., 2002) of the dichloromethane extract of $M$. thonningii seeds is most probably due to its constituent alpinumisoflavones.

O, O-dimethyl-alpinumisoflavone obtained from the dichloromethane extract of the seed and its derivatives 4'-Omethyl-alpinumisoflavone, and 5-O-methyl-4-O-(3-methylbut-2en-1-yl)-alpinumisoflavone) exhibited differential toxicity towards Brine Shrimp (Artemiasalina) (Kingsford-Adaboh et al., 2006). Furthermore, 4'-O-methyl-alpinumisoflavone isolated from Lonchocarpus glabrescens inhibited complex I activity in human breast tumor cells (Liu et al.., 2009). The present study therefore investigated the inhibitory mechanism of $\mathrm{O}$, O-dimethylalpinumisoflavone $(\mathrm{O}, \mathrm{O})$ compared with its derivative, 4'-Omethyl-alpinumsioflavone (4-O).

\section{MATERIALS AND METHODS}

\section{Materials}

Male wild type (C57BL/6) mice and Sprague-Dawley rats aged $3-5$ months were obtained from University of Cambridge. The animals were housed under controlled conditions for temperature, humidity and light, in accordance with the UK Home Office and US NIH guidelines, with water and food availability ad libitum at the University of Cambridge. The study was approved by the Ethical Review Committee of Department of Physiology, Development and Neuroscience of the University of Cambridge. All chemicals and reagents were purchased from Sigma-Aldrich, UK with the exception of $\mathrm{KH}_{2} \mathrm{PO}_{4}$ which was obtained from Merck, Germany and Imidazole purchased from Fluka, Belgium.

\section{Methods}

\section{Preparation of alpinumisoflavones from M. thonningii}

O, O-dimethyl-alpinumisoflavone and 4'-O-methylalpinumisoflavone were prepared as described previously (Kingsford-Adaboh et al., 2006). Seeds of M. thonningii collected from the University of Ghana Botanical Gardens were air dried.
These were ground into powder which was continuously soxhletextracted in methanol. Column chromatography and preparative thin-layer chromatography yielded O,O- dimethylalpinumisoflavone and 5-O-methyl-4-O-(3-methyl- but-2-en-1-yl)alpinumisoflavone. 4'-O-methyl-alpinumisoflavone was obtained by demethylating $\mathrm{O}, \mathrm{O}$ - dimethyl-alpinumisoflavone in a mixture of cold $\mathrm{BCl}_{3}$ and chloroform.

\section{Preparation of permeabilised mice cardiac fibers}

Permeabilised mouse cardiac fibers were prepared essentially as described previously (Kuznetsov et al.., 2008). Mice were euthanised by a rising concentration of $\mathrm{CO}_{2}$ followed by dislocation of the neck. The heart was removed immediately and placed in ice-cold biopsy preservation solution $(2.77 \mathrm{mM}$ $\mathrm{CaK}_{2}$ EGTA, $7.23 \mathrm{mM} \mathrm{K} \mathrm{K}_{2}$ EGTA, $20 \mathrm{mM}$ imidazole, $20 \mathrm{mM}$ taurine, $50 \mathrm{mM} \mathrm{MES,} 3 \mathrm{mM} \mathrm{K} \mathrm{HPO}_{4}, 6.5 \mathrm{mM} \mathrm{MgCl}_{2} .6 \mathrm{H}_{2}, 5.7$ $\mathrm{mM}$ ATP, $15 \mathrm{mM}$ phosphocreatine and $0.5 \mathrm{mM}$ DTT, pH 7.1). Fat and connective tissues were carefully removed and the cardiac tissue isolated into muscle strips. With the aid of sharp, nonmagnetic forceps, the strips, immersed in ice-cold isolation solution were dissected into thin muscle-fibre bundles under a dissecting microscope. The fibre bundles were transferred to a vial containing $1.7 \mathrm{ml}$ ice-cold isolation solution and $20 \mu \mathrm{l}$ of $5 \mathrm{mg} / \mathrm{ml}$ saponin and mixed gently at $4^{\circ} \mathrm{C}$ for $20 \mathrm{~min}$. The fibers were transferred to ice-cold respiration medium (0.5 mM EGTA, $3 \mathrm{mM}$ $\mathrm{MgCl}_{2} \cdot 6 \mathrm{H}_{2} \mathrm{O}, 60 \mathrm{mM}$ K-lactobionate, $20 \mathrm{mM}$ taurine, $10 \mathrm{mM}$ $\mathrm{KH}_{2} \mathrm{PO}_{4}, 20 \mathrm{mM}$ HEPES, $110 \mathrm{mM}$ sucrose and $1 \mathrm{~g} / \mathrm{L}$ BSA (fatty acid free), $\mathrm{pH} 7.1$ ) and mixed gently at $4^{\circ} \mathrm{C}$ for $5 \mathrm{~min}$. The washing step, in ice-cold respiration medium was repeated three times.

\section{Isolation of mitochondria from rat liver}

Rat liver mitochondria were isolated using differential centrifugation (Sumbalova et al.., 2015). Rats were euthanised by a rising concentration of $\mathrm{CO}_{2}$ followed by dislocation of the neck. The liver was removed immediately following cervical dislocation and placed in ice-cold isolation buffer, MSM (220 mM mannitol, $70 \mathrm{mM}$ sucrose and $5 \mathrm{Mm}$ MOPS, $\mathrm{pH}$ 7.4). The tissue was washed in $5 \mathrm{ml}$ MSM per gram liver, blot dried, minced, washed and homogenised in MSM buffer containing EDTA (1 ml of $100 \mathrm{mM}$ EDTA per $50 \mathrm{ml}$ MSM) with two strokes of loose-fitting pestle rotating at $120 \mathrm{rpm}$.

The homogenate was centrifuged at $1,700 \mathrm{rpm}$ for $10 \mathrm{~min}$ and supernatant saved. The supernatant was centrifuged at 7,650 rpm for $10 \mathrm{~min}$ and pellet saved. The pellet was resuspended in 5 $\mathrm{ml}$ MSM per gram liver and centrifuged at 7,650 rpm for $10 \mathrm{~min}$. The resuspension and centrifugation was repeated in $2.5 \mathrm{ml}$ MSM per gram liver. The final pellet was suspended in $0.2 \mathrm{ml} \mathrm{MSM} \mathrm{per}$ gram liver and protein concentration determined. All centrifugations were carried at $4^{\circ} \mathrm{C}$.

\section{Determination of protein concentration}

The protein concentration of the isolated mitochondria was determined using the Bio-Rad protein quantification kit (BioRad, Richmond, CA, USA) following the manufacturer's protocol 
with bovine serum albumin $(0-2 \mathrm{mg} / \mathrm{ml})$ as standard. Mitochondria were diluted 1 in 20 with isolation buffer. To $5 \mu 1$ of the standards and diluted sample was added $200 \mu \mathrm{l}$ of $1 \mathrm{x}$ dye reagent, mixed thoroughly and incubated on rocker-shaker for $5 \mathrm{~min}$. Absorbance read at $595 \mathrm{~nm}$ using a 90-well microtitreplate reader and protein concentration was estimated from a calibration curve from the serum albumin standard.

\section{Measurement of mitochondrial respiration in permeabilised heart fibers}

The mitochondrial oxygen consumption in presence of various substrates and inhibitors was measured in presence and absence of the plant extracts using a Clark-type oxygen electrode (782 oxygen electrode system, Strathkelvin Instruments, UK). The permeabilised fibers $(2.0-2.5 \mathrm{mg}$ wet weight $)$ were preincubated for $1 \mathrm{~min}$ with $0.5 \mu \mathrm{l}$ of $35 \mathrm{mg} / \mathrm{ml}$ of $\mathrm{O}$, O-dimethylalpinumisoflavone or 4'-O-methyl-alpinumisoflavone dissolved in DMSO, with the same volume of DMSO alone used as a control, in $0.5 \mathrm{ml}$ of air-saturated respiration medium in the electrode chamber at $37^{\circ} \mathrm{C}$. A substrate-inhibitor titration was then used, as described previously (Kuznetsov et al.., 2008), to elucidate respiratory chain function (Fig. 1).

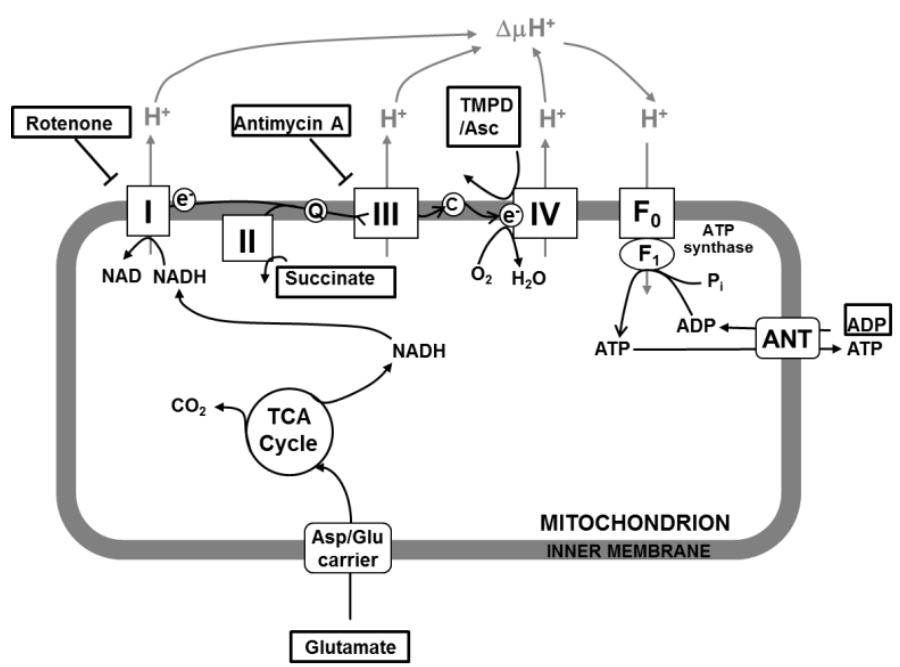

Fig. 1: The metabolic fates of mitochondrial energy substrates.

Glutamate enters the mitochondrion via the aspartate/glutamate carrier and is oxidised to $\alpha$-ketoglutarate by glutamate dehydrogenase and the $\alpha$ ketoglutarate is metabolised in the tricarboxylic acid cycle (TCA) in presence of malate. NADH produced by reduction of $\mathrm{NAD}^{+}$is oxidised by complexes $\mathrm{I}$, of the electron transport chain, which consists of complexes I-IV. Electrons are transferred through the chain to the final acceptor, $\mathrm{O}_{2}$. The free energy from electron transfer is used to pump $\mathrm{H}^{+}$out and generate an electrochemical gradient, $\Delta{\mu_{\mathrm{H}}}^{+}$, across the inner mitochondrial membrane, which is the driving force for ATP synthesis via ATP synthase. (Figure adapted from Cole et al.., 2011)

Briefly $2 \mathrm{mM}$ malate and $10 \mathrm{mM}$ glutamate $(\mathrm{G}+\mathrm{M})$ were added to stimulate State 2 respiration via Complex I before $5 \mathrm{mM}$ ADP was added to activate oxidative phosphorylation (State 3 respiration). Next, $1 \mu \mathrm{M}$ Rotenone (Rot) was added to inhibit
Complex I, before $10 \mathrm{mM}$ succinate (Succ) was used to stimulate respiration via Complex II. Next, $2.5 \mu \mathrm{M}$ Antimycin A was used to inhibit Complex III and thus all respiration supported by substrates for Complexes I and II. Finally $2 \mathrm{mM}$ Ascorbate and $0.5 \mathrm{mM}$ N,N,N',N'-tetramethyl-p-phenylenediaminedihydrochloride

(TMPD) (Asc+TMPD) were added to support respiration via Complex IV before $10 \mu \mathrm{M}$ Cytochrome $\mathrm{C}$ was added to assess outer mitochondrial membrane intactness. Oxygen consumption was allowed to reach steady state following each addition, and the rate of respiration was analysed using the 782 system software (Strathkelvin Instruments, UK). Respiration rates are presented as oxygen consumption per mg wet weight of tissue.

\section{Measurement of mitochondrial respiration in isolated mitochondria}

The mitochondrial oxygen consumption was measured in presence and absence of the compounds using a Clark-type oxygen electrode as indicated above. The isolated mitochondria $(1 \mathrm{mg}$ protein) were preincubated for $1 \mathrm{~min}$ with $0.5 \mu \mathrm{L}$ of $35 \mathrm{mg} / \mathrm{ml}$ of O, O-dimethyl-alpinumisoflavone or 4'-O-methylalpinumisoflavone dissolved in DMSO, with the same volume of DMSO alone used as a control, in $0.5 \mathrm{ml}$ of air-saturated respiration medium in the electrode chamber at $37^{\circ} \mathrm{C}$.Glutamate (10 $\mathrm{mM})$ was added to stimulate State 2 respiration via complex I, followed by addition of $1 \mathrm{mM}$ ADP to activate oxidative phosphorylation (State 3 respiration). Oxygen consumption was allowed to continue until all the ADP was used up (State 4 respiration). This was followed by addition of FCCP to completely uncouple the mitochondria. The procedure was repeated with 10 $\mathrm{mM}$ succinate except that FCCP was not added after State 4 respiration and with2 $\mathrm{mM}$ Ascorbate and $0.5 \mathrm{mMTMPD}$ (Asc+TMPD), where State 4 respiration could not be recorded. The rate of respiration was analysed as indicated above and Respiratory Control Ratio (RCR) was calculated as State 3/State 4 respiration as a measure of mitochondrial coupling (Gnaiger, 2009).

\section{Statistical analysis}

All data were presented as mean \pm S. E. M. Comparisons between means were performed and significance was evaluated by one-factor analysis of variance (ANOVA) using Microsoft Excel. Probability value of $p<0.05$ was used as the criteria for significant differences.

\section{RESULTS}

\section{Effect on mitochondria in permeabilised mouse heart fibers}

To investigate whether the alpinumisoflavones $(\mathrm{O}, \mathrm{O}$ dimethyl-alpinumisoflavone and 4'-O-methyl-alpinumisoflavone) inhibit mitochondrial respiratory chain activity in situ, permeabilised mice heart fibers were titrated with different substrates and inhibitors and mitochondrial oxygen consumption measured in presence of either the solvent (DMSO) or the compounds. As shown in figure 2, incubation of the permeabilised 
tissue with either the solvent (DMSO) or the compounds did not result in appreciable consumption of oxygen. Addition of $\mathrm{G}+\mathrm{M}$ to stimulate complex I (Cole et al.., 2011) resulted in a minimal increase in oxygen consumption (State 2 respiration) both in presence and absence of the two compounds. Oxygen consumption increased by about three-fold upon addition of ADP (State 3 respiration) and this was significantly inhibited by 4'-Omethylalpinumisoflavone $(\mathrm{p}=0.001)$ and $\mathrm{O}$, O-dimethylalpinumisoflavone $(\mathrm{p}=0.002)$. Addition of rotenone, a potent inhibitor of complex I brought oxygen consumption approximately back to the basal (State 2) level in presence and absence of the two compounds. Succinate stimulates complex II and therefore increased respiration in presence of rotenone. This succinatestimulated respiration was however significantly lower $(\mathrm{p}<0.001)$ in presence of the two compounds. Antimycin A inhibits complex III and therefore brought oxygen consumption back to the basal level either in presence or absence of both compounds. Addition of Asc+TMPD, artificial electron donor to cytochrome oxidase resulted in increased oxygen consumption, which was significantly inhibited by the4'-O-methyl-alpinumisoflavone $(\mathrm{p}=0.01)$ and the O, O-dimethyl-alpinumisoflavone $(\mathrm{p}=0.02)$.

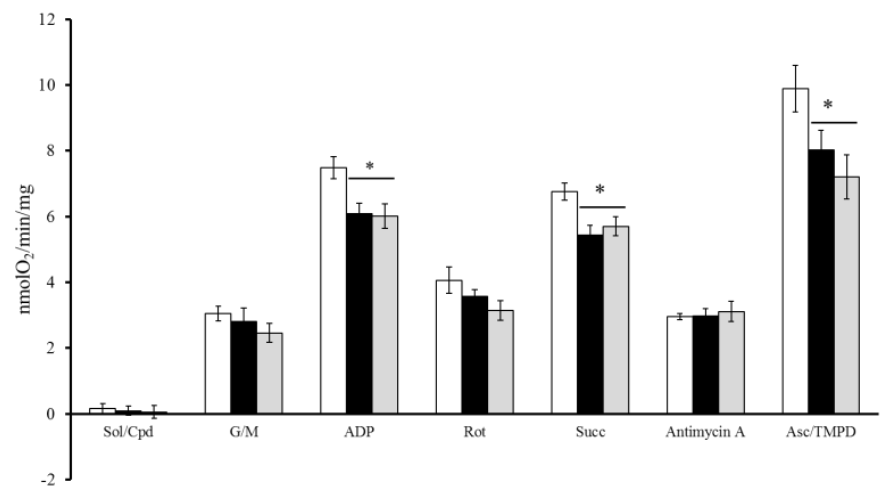

Fig. 2: Effect of the alpinumisoflavones on mitochondrial respiratory chain activity in permeabilised mouse heart fibers: Solvent (DMSO); white bars, O, O-dimethylalpinumisoflavone; black bars and 4'-O-methylalpinumisoflavone; grey bars. Values are mean \pm S.E.M. of 4 independent analysis. *significantly different from solvent (DMSO) $(\mathrm{p}<0.05)$.

\section{Effect on isolated rat liver mitochondria}

The inhibitory effects of the two alpinumisoflavones were probed further by measuring oxygen consumption of isolated rat liver mitochondria using glutamate, succinate and Asc+TMPD separately as substrates. The uncoupled respiration was also measured in presence of FCCP. As shown in Figure 3a, in presence of glutamate to stimulate complex I, both compounds significantly inhibited State 3 respiration $(p=0.001)$, uncoupled respiration $(\mathrm{p}<0.0001)$ and consequently decreased the Respiratory Control Ratio (RCR) ( $<<0.03)$ (Table 1). States 2 and 4 respirations were however not affected (Fig. 3a). Intriguingly, in presence of succinate as a substrate to stimulate Complex II, the O,O-dimethyl-alpinumisoflavone did not significantly alter any of the respiration parameters whereas the 4'-Omethylalpinumisoflavone caused slight but significant decrease in
State 2 respiration $(\mathrm{p}=0.02$ ) (Fig. 3b). For the Asc+TMPD stimulated respiration (Fig. 3c), the 4'-O-methylalpinumisoflavone significantly decreased State 3 respiration $(\mathrm{p}=0.02)$ but the $\mathrm{O}, \mathrm{O}$ dimethyl-alpinumisoflavone did not significantly alter any of the respiration parameters.

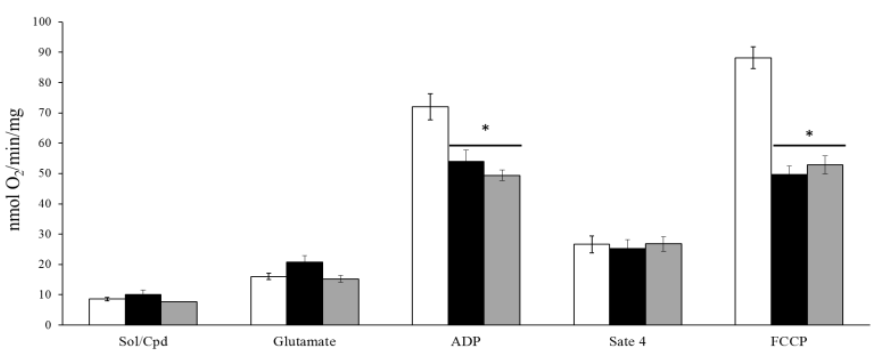

A
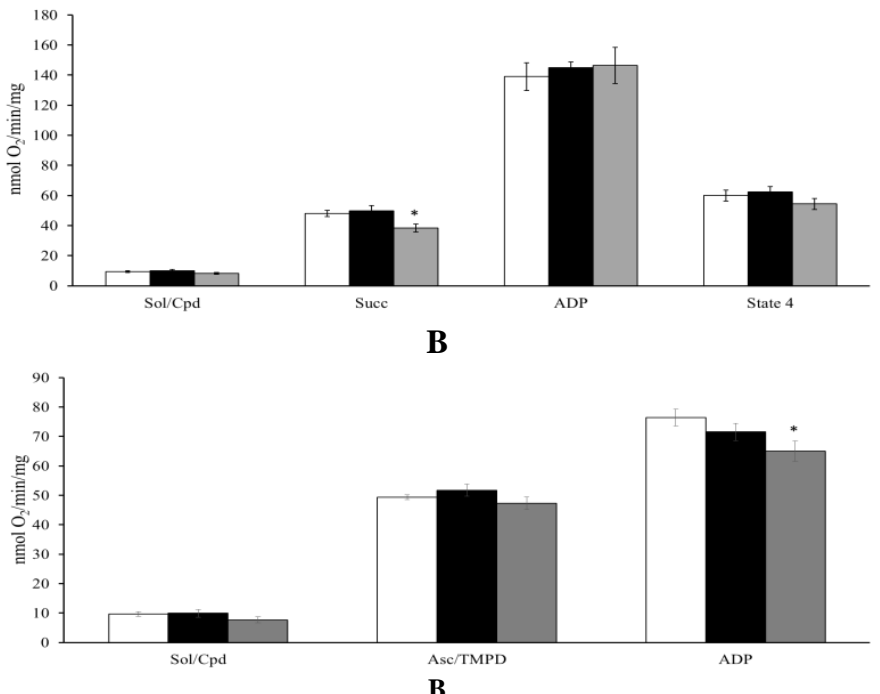

Fig. 3: Effect of the alpinumisoflavones on mitochondrial respiratory chain activity of isolated rat liver mitochondria: a: Glutamate stimulated (Complex I), b: Succinate stimulated (Complex II) and c: Asc/TMPD stimulated (Complex IV). Solvent (DMSO); white bars, O, O-dimethylalpinumisoflavone; black bars and 4'-O-methylalpinumisoflavone; grey bar. Values are mean \pm S.E.M. of 4 independent analysis. *significantly different from solvent (DMSO) $(\mathrm{p}<0.05)$.

Table 1: Respiratory control ratio (RCR) of isolated rat liver mitochondrial respiring on Glutamate as Complex I substrate

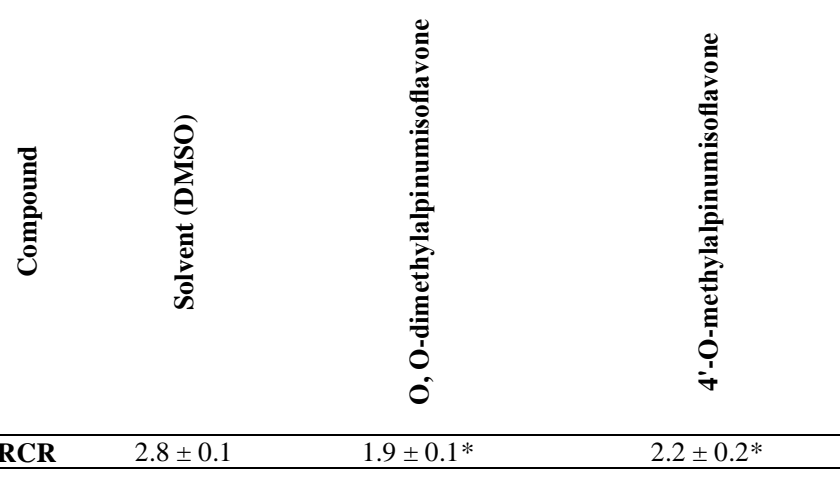

Values are mean \pm S.E.M. of 4 independent analysis. *significantly different from solvent $(\mathrm{DMSO}) \quad(\mathrm{p}<0.05)$. 


\section{DISCUSSION}

The present study examined the effects of $\mathrm{O}$, Odimethyl-alpinumisoflavone and 4'-O-methyl-alpinumisoflavone on mitochondrial respiratory chain activity both in vitro and in situ with the overall goal of assessing whether the alpinumisoflavones present in the crude dichloromethane extract of the M. thonningii seeds are responsible for the reported complex I inhibition effect. In permeabilised cardiac fibers, addition of glutamate and malate. Intriguingly, O, O-dimethyl-alpinumisoflavone exhibited complex I inhibitory property by inhibiting State 3 respiration in presence of glutamate/malate and glutamate in permeabilised mice cardiac fibers (in situ) (Fig. 2) and isolated rat liver mitochondria (Fig. 3a) respectively. Thus, the present study did not only support the complex I inhibition by phyto-constituent(s) of the extract of $M$. thonningii seeds (Lyddiard and Whitfield, 2001) but also strongly points to the fact that $\mathrm{O}$, O-dimethyl-alpinumisoflavone might be the active phyto-constituent in $M$. thonningii with complex I inhibition action. Additionally, the inhibition of the uncoupled respiration by $\mathrm{O}$, O-dimethyl-alpinumisoflavone in the present study indicates that the compound indeed does not interfere with the phosphorylation mechanism but rather the electron transfer system as reported previously. However, contrary to the report by Lyddiard and Whitfield, (2001) on the crude extract, the present study has demonstrated that $\mathrm{O}$, O-dimethyl-alpinumisoflavone does not interfere with rotenone, a potent inhibitor of complex I. Thus, suggesting that in spite of the structural similarity between this alpinumisoflavone and rotenone, the two compounds do not compete for binding sites on complex I of the respiratory chain as suggested previously.

Similarly, the 4'-O-methyl-alpinumisoflavone exhibited complex I inhibitory property (Fig. 3a). It also inhibited uncoupled respiration and did not interfere with rotenone inhibited and State 4 respirations (Fig. 2). Thus, similar to the O, O-dimethylalpinumisoflavone, 4'-O-methyl-alpinumisoflavone inhibited the electron transport system and not the phosphorylation process. However, unlike O, O-dimethyl-alpinumisoflavone, 4'-O-methylalpinumisoflavone exhibited complexes II and IV inhibition effects by significantly decreasing State 3 respiration in presence of succinate and Asc/TMPD in both the permeabilised mice cardiac fibers (Fig. 2) and the isolated rat liver mitochondria (Fig. 3a-c). It also inhibited succinate stimulated State 2 respiration in the isolated rat liver mitochondria (Fig. 3b). Contrary to previous report (Liu et al.., 2009), the present findings have shown that 4'O-methyl-alpinumisoflavone does not only inhibit the complex I of the respiratory chain but also complexes II and III. The present report however supports previous finding (Liu et al.., 2009) that 4'O-methyl-alpinumisoflavone do not act in the same was as rotenone, a complex I inhibitor.

Although the reason for the observed differences in effect of the O, O-dimethyl-alpinumisoflavone on the permeabilised mice cardiac fibers (in situ) as compared to the isolated rat liver mitochondria (in vitro) is unclear, it is most probablydue tothe requirement of co-factors and/or differences in mitochondrial dynamics in the two preparation protocol. Whiles, the cytoplasmic co-factors and mitochondrial network and dynamics are retained in mitochondria in permeabilised tissues; they are completely lost inisolated mitochondria (Gnaiger, 2014; Picard et al.., 2011). Thus, compounds that need to be transformed to their active form will produce no effect in isolated mitochondria but in mitochondria in permeabilised tissues. Consequently, the inhibitory effect of $\mathrm{O}$, O-dimethyl-alpinumisoflavone could be dependent on some co-factor or other cellular component that is present in the permeabilised fibre preparation but absent in the isolation mitochondria.

\section{CONCLUSION}

Whilst O, O-dimethyl-alpinumisoflavone, a naturally occurring phyto-constituent of extract of $M$. thonningii seeds inhibited mitochondrial respiratory chain activity at complex I, its derivative 4'-O-methyl-alpinumisoflavone, a naturally occurring phyto-constituent of Lonchocarpus glabrescens exhibited complexes I, II and IV inhibitory effect.

\section{ACKNOWLEDGEMENT}

The authors are grateful to Carnegie Corporation of New York, the Alborada Research Fund, UK, the Cambridge-Africa Partnership for Research Excellence (CAPREx), the University of Cambridge and University of Ghana, Legon for financial support.

Conflict of Interests: There are no conflicts of interest.

\section{REFERENCES}

Banzouzi, JT, Prost, A, Rajemiarimiraho, M and Ongoka, P. Traditional uses of African Millettia species (Fabaceae). Int J Bot, 2008; 4(4):406-420.

Cerella, C, Radogna, F, Dicato, M and Diederich, M, Natural Compounds as Regulators of the Cancer Cell Metabolism. Int J Cell Biol, 2013; 1-16.

Cole, MA, Murray, AJ, Cochlin, LE, Heather, LC, McAleese, S, Knight, NS, Sutton, E, Jamil, AA, Parassol, N and Clarke, KA high fat diet increases mitochondrial fatty acid oxidation and uncoupling to decrease efficiency in rat heart. Basic Res Cardiol, 2011; 106:447-457.

Evans, NA, Whitfield, PJ, Squire, BJ, Fellows, LE, Evans, SV and Millot, SM. Molluscicidal activity in the seeds of Millettia thonningii (Legumino- sae: Papilionideae). Trans Royal Soc Trop Med Hygiene, 1986; 80:451-453.

Forbes-Hernandez, TY, Giampieri, F, Gasparrini, M, Mazzoni, L, Quiles, JL, Suarez, A-JM and Battino, M. The effects of bioactive compounds from plant foods on mitochondrial function: A focus on apoptotic mechanisms. Food Chem Toxicol, 2014; 68:154-182.

Giorgi, C, Agnoletto, C, Bononi, A, Bonora, M, De Marchi, E, Marchi, S, Missiroli, S, Patergnani, S, Poletti, F, Rimessi, A, Suski, JM, Wieckowski, MR and Pinton, P. Mitochondrial calcium homeostasis as potential target for mitochondrial medicine. Mitochondrion. 2012; 12(1): $77-85$.

Gnaiger, E. Isolated mitochondria or permeabilised tissues and cells in Mitochondrial Physiology Network (2014); 11.05(06): 1-5.

Gnaiger, E. (ed). Mitochondrial Pathways and Respiratory Control. 2nd ed, OROBOROS MiPNet Publications, Innsbruck: 2009; pp. 43-53.

Gohil, VM, Sheth, SA, Nilsson, R, Wojtovich, AP, Lee, JH, Perocchi, F, Chen, W, Clish, CB, Ayata, C, Brookes, PS and Mootha, VK. 
Nutrient-sensitized screening for drugs that shift energy metabolism from mitochondrial respiration to glycolysis. Nature Biotechnol, 2010; 28:249255 .

Greaves, LC, Reeve, AK, Taylor, RW and Turnbull, DM. Mitochondrial DNA and disease. J Pathol, 2012; 226:274-286.

Harrison, EKJJ, Dankyi, E, Kingsfordadaboh,R, Ishida, H. In search of new leads: a closer look at the therapeutic potential of the Constituents of Millettia thonningii, Millettia pachycarpa and their Structural analogues. Intl J Pharm Pharm Sci, 2011; 3(2):71-81.

Kingsford-Adaboh, R, Dittrich, B, Hubschle, CB, Gbewonyo, WSK, Okamoto, $\mathrm{H}$, Kimura, $\mathrm{M}$ and Ishida, $\mathrm{H}$. Invariom structure refinement, electrostatic potential and toxicity of 4- $\mathrm{O}$ methylalpinumisoflavone, $\mathrm{O}, \mathrm{O}$-dimethylalpinumisoflavoneand 5- O methyl-4- O -(3-methylbut-2-en-1-yl)alpinumisoflavone. Acta Cryst. 2006; B62:843-849.

Kuhlbrandt, W. Structure and function of mitochondrial membrane protein complexes. BMC Biol. 2015; 13:89 DOI: 10.1186/s12915-015-0201-x

Kuznetsov, AV, Veksler, V, Gellerich, FN, Saks, V, Margreiter, $\mathrm{R}$ and Kunz, WS. Analysis of mitochondrial function in situ in permeabilized muscle fibers, tissues and cells. Nature Prot, 2008; 3(6):965-976.

Liu, Y, Veena, CK, Morgan, BJ, Mohammed, KA, Jekabsons, MB, Nagle, DG and Zhou, YD. Methylalpinumisoflavone Inhibits Hypoxia-inducible Factor-1 (HIF-1) Activation by Simultaneously Targeting Multiple Pathways. J Biol Chem, 2009; 284(9):5859-5868.

Lyddiard, JRA, Bartlett, A, Gray, B and Whitfield, PJ. The use of video-imaging to assess the sub- lethal impact of plant secondary compounds on Schistosoma mansoni miracidia. J Helminthol, 1998; 72:237-241.

Lyddiard, JRA, Whitfield, PJ and Bartlett, A. Antishistosomal bioactivity of isoflavonoids from Millettia thonningii (Leguminosae). J Parasitol, 2002; 88:163-170.

Lyddiard, JRA and Whitfield, PJ. Inhibition of Site I mitochondrial electron transport by an extract of the seeds of Millettia thonningii: a potential mechanism for the plant's molluscicidal and schistosomelarvicidal activity. J Helminthol, 2001; 75:259 265.

Moncada, S. Mitochondria as pharmacological targets. British J Pharmacol, 2010; 160:217-219.
Namkoong, S, Kim, TJ, Jang, IS, Kang, KW, Oh WK and Park, J. Alpinumisoflavone Induces Apoptosis and Suppresses Extracellular Signal-Regulated Kinases/Mitogen Activated Protein Kinase and Nuclear Factor- k k B Pathways in Lung Tumor Cells. Biol Pharm Bull, 2011; 34(2):203-208.

Picard, M, Taivassalo, T, Ritchie, D, Wright, KJ, Thomas, MM, Romestaing, C and Hepple, RT. Mitochondrial Structure and Function Are Disrupted by Standard Isolation Methods. PLoS ONE 2011; 6(3):e18317. doi:10.1371/journal.pone.0018317

Perrett, S, Whitfield, PJ, Bartlett, A and Sanderson, L. Attenuation of Schistosoma mansoni cercariae with a molluscicide derived from Millettia thonningii. Parasitol, 1994; 109:559-563.

Squire, BJ and Whitfield, PJ. Millettia thonningii: a rapid knockdown cercaricide for schistosomecercariae. Phytotherapy Res, 1989; 3:112-114.

Sumbalova, Z, Fontana-Ayoub, M and Krumschnabel, G. Laboratory protocol: isolation of rat liver mitochondria. Mitochondrial Physiology Network 2015; 20.08(01):1-2.

Tait, SWG and Green, DR. Mitochondria and cell death: outer membrane permeabilization and beyond. Nature Rev Mol Cell Biol, 2010; 11:621-632.

Tang, SSH, Whitfield, PJ and Perrett, S. Activity of the molluscicidal plant Millettia thonningii (Legumi- nosae) towards Biomphalaria glabrata eggs. J Parasitol, 1995; 81:833-835.

Toogood, PL. Mitochondrial drugs. Curr Opinion Chem Biol, 2008; 12:457-463.

Wallace, KB and Starkov, AA. Mitochondrial targets of drug toxicity. Ann Rev Pharmacol, Toxicol. 2000; 40:353-88.

\section{How to cite this article:}

Ocloo A, Kingsford-Adaboh R, Murray AJ. Inhibition of Mitochondrial Respiratory Chain Activity By O, O-Dimethyl- and 4-O- Methyl- Alpinumisoflavones. J App Pharm Sci, 2017; 7 (03): 095-100. 